\title{
Initiation and Termination of Oriental Fruit Moth Male Response to Pheromone Concentrations in the Field ${ }^{1}$
}

\author{
T, C. BAKER ${ }^{2}$ AND W. L. ROELOFS \\ Department of Entomology, New York State Agricultural Experiment Station, Geneva, New York \\ ABSTRACT \\ Environ. Entomol. 10: 211-218 (1981)
}

The distance from the pheromone source at which Grapholitha molesta (Busck) males initiated walking, upwind flight, or wing fanning while walking varied directly with the pheromone emission rate. Roughly a 10 -fold increase in emission rate resulted in a ca. 2fold increase in mean maximum distance for initiation of these behaviors. Also, an apparent upper concentration threshold in males caused upwind flight to be terminated at increasing distances from the source with increasing emission rates. Thus, upper and lower thresholds apparently determine the boundaries of the "active distance" for upwind flight. There was much daily variation in mean maximum active distance, possibly due to temperature effects upon male threshold. The active distance estimates were used to design an optimal monitoring trap deployment strategy to minimize attraction of males from areas surrounding orchards. Using Bossert and Wilson's equation for active space, the average lower (initiation) threshold for upwind flight was $7.2 \times 10^{-17} \mathrm{~g} / \mathrm{cm}^{3}$ and the upper (termination) threshold was $2.1 \times 10^{-13} \mathrm{~g} / \mathrm{cm}^{3}$. Their model should be altered so that active space is defined as the space where pheromone concentration is within both lower and upper thresholds for a particular behavior.

\section{Introduction}

In recent years, the pheromone monitoring trap has become a valuable tool in the management of lepidopterous pests. While providing essential information on adult population peaks for insecticide spray timing or pretictive phenological models (Reidl et al. 1976, Welch et al. 1978), its usefulness for estimating population density has been limited by a number of factors. One is the lack of knowledge of the drawing range of such traps, without which even rudimentary absolute density estimates cannot be made. Correlating relative capture frequencies directly to economic injury levels would seem one way around the population estimate problem, yet correlation accuracies still depend upon variations in the traps' drawing ranges. For example, traps may attract males from outside the crop area, resulting in an overestimation of the female population within the crop. Such an error would presumably occur more frequently with smaller plot sizes or with traps placed closer to crop borders, but we can only speculate until actual drawing range measurements are made.

We wanted to make such measurements using several Grapholitha molesta (Busck) (Oriental fruit moth) sex pheromone blend dosages, since we felt that dosagedependent drawing range variation might allow traps to be tailored for optimal positioning within an orchard. Also, because pheromone emission rates had been determined for some of the dosages (Baker et al. 1980), we were interested in estimating male response thresholds and how they interact with emission rates to define the "active distance" of pheromone communication

\section{Materials and Methods}

\section{Chemicals}

The following have been identified as $G$. molesta sex pheromone components and were used in this study: $(Z)$ -

\footnotetext{
'Received for publication March 24, 1980.

3 Present address: Division of Toxicology and Physiology, Department of Entomology, University of Californis, Riverside, CA 92521.
}

8-dodecenyl acetate (Z8-12:Ac) (Roelofs et al. 1969 A.M. Cardé et al. 1979), (E)-8-dodecenyl acetate (E812:Ac) and (Z)-8-dodecenyl alcohol (Z8-12:OH) (A. M. Cardé et al. 1979, Biwer et al. 1979). The Z8-12:Ac was purchased from Farchan Corporation and found to contain over $3 \%$ of the $(E)$ isomer as checked on a $10 \%$ XF-1150 (50\% cyanoethyl methylsilicone on 100-120 mesh Chromosorb W-AW-DMCS) $2 \mathrm{~m} \times 2 \mathrm{~mm}$ ID glass GLC (gas-liquid chromatography) column in a Packard model 7300 series gas chromatograph. An $\mathrm{H}_{2}$ flame ionization detector was used, and $\mathrm{N}_{2}$ at $25 \mathrm{ml} / \mathrm{min}$ was the carrier gas. Oven temperature was $160^{\circ} \mathrm{C}$. Retention times were $3.1,3.4$, and $3.8 \mathrm{~min}$ for E8-12:Ac, Z8$12: A c$, and $\mathrm{Z} 8-12: \mathrm{OH}$, respectively. We purified the $\mathrm{Z} 8$ 12:Ac by low pressure liquid chromatography using a high-capacity $2.5 \mathrm{~cm}$ I.D. glass column packed with 46 $\mathrm{cm}$ of $20 \% \mathrm{AgNO}_{3}$ on Silica Gel H${ }^{\circledast}$ (30-70 mesh) (J. T. Baker Co.) using a 95:5 Skellysolve-B:ethyl acetate solvent system flowing at $5 \mathrm{ml} / \mathrm{min}$. The resulting purified Z8-12:Ac contained $0.04 \%$ of the $(E)$ isomer, determined by GLC analysis on XF-1150 (using peak height $\times$ retention time), no detectable $28-12: \mathrm{OH}$, and less than $0.1 \%$ other volatile impurities. The E8-12:Ac, obtained from Farchan Corp., also was purified on the $20 \% \mathrm{AgNO}_{3}$ HPLC column. The resulting E8-12:Ac contained no detectable $(Z)$ isomer or $Z 8-12: O H$, and less than $0.5 \%$ other volatile impurities. The $\mathrm{Z} 8-12: \mathrm{OH}$, made by saponifying the above-purified Z8-12:Ac, contained $0.1 \%$ Z8-12:AC, $0.04 \%$ E8-12:OH, no detectable E8-12:Ac, and less than $0.2 \%$ other volatile impurities as checked on XF-1150. The final three-component blend checked on XF-1150 was 5.9\% E8-12:Ac and $3.8 \% \mathrm{Z8}-12: \mathrm{OH}$ in $\mathrm{Z8}-12: \mathrm{Ac}$, formulated according to the optimal ratio of Baker and Cardé (1979a).

\section{Rearing and Handling}

$G$. molesta males were reared on small green thinning apples on a $16: 8$ light:dark photoperiod regime at $25^{\circ} \mathrm{C}$ and variable humidity. Light:dark lighting intensities 
were 1400 and less than 0.3 lux, respectively. Pupae were segregated by sex and the adult males were held at $25^{\circ} \mathrm{C}$ on a $16: 8$ photoperiod regime in $33 \times 27 \times 31$ $\mathrm{cm}$ screen cages in rearing rooms where no females were kept. Males were additionally segregated by daily age, and were divided into two groups in which scotophase (dark phase) commenced at 1100 and $1500 \mathrm{~h}$, respectively. This photoperiod shift allowed behavioral observations to be performed outdoors in the morning or afternoon at $0-3 \mathrm{~h}$ before scotophase, the period of optimum pheromone response for $G$. molesta (Baker and Cardé, 1979b). Males for the mark-release-recapture experiment, however, were held on a 16:8 regime with lights-off at $2030 \mathrm{~h}$ to coincide with outdoor conditions.

\section{Measurements of Mean Maximum Active Distance of Response Initiation}

We used a large treeless recreation area with ca. 10 cm-high grass at the Geneva Experiment Station for these measurements. A small part of the ca. $10,000 \mathrm{~m}^{2}$ triangular-shaped area was a gravel parking lot and was bordered by trees on two sides and a building on the third. This experimental field had two desirable characteristics. One was the lack of turbulence-producing obstructions or pheromone-adsorptive surfaces, and the other was the lack of surfaces that could harbor calling females (of other species) interfering with the measurements. $G$. molesta female interference also was minimized by conducting experiments in morning or afternoon using males on shifted photoperiod schedules.

Pheromone was emitted from $1,10,100$, or $1000 \mu \mathrm{g}$ loaded rubber septa (A. H. Thomas, \#8753-D22, sleeve type) impaled, large opening skyward, on an insect pin taped to the top of a $1.7 \mathrm{~m}$ high, $5 \mathrm{~cm}$ diam. steel pole anchored by a cement base. The septum's vertical positioning made the chemical plume free of directionally biased septum turbulence. The pin and top of the pole were rinsed with acetone whenever septa were changed. A smoke plume-generating apparatus was located $3 \mathrm{~m}$ away to indicate wind direction and to provide a parallel but separate marker for pheromone plume position. Ammonium chloride smoke was produced by pumping air from a vacuum pump through separate flasks containing concentrated hydrochloric acid and ammonium hydroxide. The vapors traveled up separate tubes whose openings met at the top of an identical $1.7 \mathrm{~m}$ high pole where a dense plume of bluish-white smoke formed. Depending on the predominant wind direction, the pheromone and smoke sources were maneuvered to minimize the plumes' overlap as the smoke could affect male behavior.

A cage of 4-5-day-old males was kept $50-100 \mathrm{~m}$ upwind of the pheromone source. Immediately before testing, 3 males were removed and placed together in an $8 \mathrm{~cm}$ high $\times 10 \mathrm{~cm}$ basal diam. screen cone completely open at the base. After the males became quiescent, an observer began walking slowly toward the pheromone source from several hundred meters downwind, with the open end of the cone held upwind at eye level. The walker tried to keep the smoke approximately 3-5 meters to the side at all times to maximize exposing the males to pheromone at all distances. A distinct smoke plume was not usually visible past $50 \mathrm{~m}$ and so phero- mone plume position often had to be inferred by observing the smoke's direction from a distance. Very little upwind, mostly lateral, walking was used with rapidly changing wind directions to maintain position with respect to the smoke but whenever the direction stabilized, the observer walked mostly upwind with small (less than $5 \mathrm{~m}$ ) lateral oscillations. Upwind advancement also was prohibited when wind velocity exceeded $1.5 \mathrm{~m} / \mathrm{sec}$, as monitored on a Hastings-Raydist hot-wire anemometer by another observer near the source. Velocities above $1.5 \mathrm{~m} / \mathrm{sec}$ significantly reduced to nearly 0 the frequency of flight initiation by males in a laboratory wind tunnel (see Results). Progress toward the source during high velocities, therefore, would have biased against upwind flight active distances relative to those of walking and wing fanning while walking.

While walking, the observer watched the males through the back of the cone. Two of the 3 behaviors monitored, walking and wing fanning while walking were scored either when one male exhibited the behavior for 3 or more continuous seconds, or at least 2 of the 3 males exhibited the behavior simultaneously regardless of duration. Upwind flight was scored when any of the 3 males flew upwind out of the cage, regardless of duration. Flight trajectory was nearly always upwind initially, but it was not possible to follow males for more than a few meters owing to their small size and high flight velocity. The upwind approach of flying males, therefore, was measured in a second experiment described in the next section. The observer dropped flags coded for the behavior, pheromone dosage, and replicate at the site where the behavior was first observed. Wind velocity at the time each flag was dropped was recorded by the second observer stationed with the anemometer. Distances to the flags from the pheromone source were measured at the completion of the observations. Cones were used once per experiment and rinsed with acetone between uses.

\section{Measurements of Mean Active Distance of Upwind Flight Termination}

A septum containing one of the same four dosages used above and impaled upright on an insect pin was attached to the top of a $0.5 \mathrm{~cm}$ diam. steel rod in the ground so that the septum was ca. $15 \mathrm{~cm}$ above the grass. Concentric string circles with radii of 10,30 , 100 , and $300 \mathrm{~cm}$ were placed around the septum. Observations were performed between 1200 and $1500 \mathrm{~h}$ using 4-5-day-old males at $0-3 \mathrm{~h}$ before onset of laboratory scotophase. After approaching from sidewind, the observer placed on the grass $5 \mathrm{~m}$ directly downwind of the septum a screen cone containing a single male. The male's flight was then followed and scored for the closest approach to the septum using the string circles as guides. A second observer stationed $\mathrm{ca}$. one $\mathrm{m}$ to the septum's side aided in tracking, capturing, and disposing of the males after they either touched the septum or terminated upwind flight. Only one upwind approach per male was allowed.

\section{Mark-Release-Recapture}

From July 16 to August 3, 1979, at ca. $4 \mathrm{~h}$ before sunset 2-5-day-old males were placed, 20 per bag, in 
4-liter polyethylene bags containing a ca. $100 \mathrm{mg}$ of Dayglo ${ }^{\text {pit }}$ fluorescent powder. The bags were agitated to dust the males with sufficient powder to be visible later under ultraviolet light. The powder's color was the code for the distance from a central pheromone trap at which these males were to be released. Four release points (20 males/release point) were $24.4 \mathrm{~m}$ from the trap, 4 were at $12.2 \mathrm{~m}, 2$ at $6.1 \mathrm{~m}$ (40 males total), and 1 was at the trap tree itself (Fig. 1). At ca. $2.5 \mathrm{~h}$ before sunset the bags were placed beneath their release-trees in each of two semi-dwarf orchard plots, separated by $40 \mathrm{~m}$. On signal, workers in each plot began releasing males into the canopy of each tree by gently opening and shaking the bags. All males were released within 10 minutes, and within the next 5 minutes, the Pherocon ${ }^{(0)}$ IC traps were deployed. One trap contained a $10 \mu \mathrm{g}$ dose, the other a $100 \mu \mathrm{g}$ dose per septum of the pheromone blend described earlier.

Traps were taken down the next morning and the males examined under UV light. Before a new replicate was run, other traps were placed in the orchards for at least 3 days to capture colored males left in the area.

\section{Effects of Wind Velocity and Temperature}

Wind velocity effects were observed in a $2.0 \times 0.89$ $\times 0.96 \mathrm{~m}$ laboratory wind tunnel (Miller and Roelofs, 1978). Three males contained in a screen cone like that described earlier were placed on a $15 \mathrm{~cm}$-high platform $1 \mathrm{~m}$ downwind from a fan with the cone's open end facing upwind. At random 1 of 4 wind velocities was

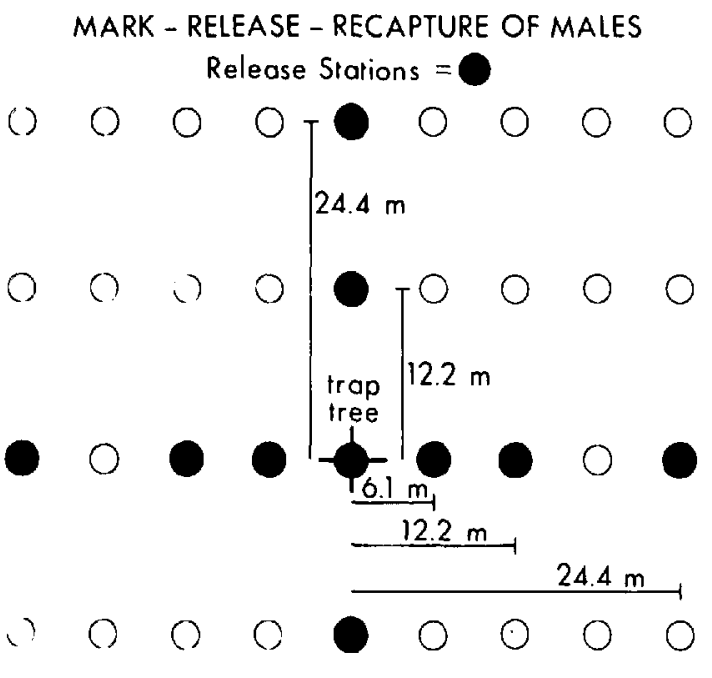

$$
\begin{aligned}
& \text { () () O O O } \\
& \text { af } 6.1 \mathrm{~m}(2 \mathrm{sta} \text {. } \\
& \text { at } 12.2 \mathrm{~m} \text { (4 sta.) } \\
& \text { at } 24.4 \mathrm{~m} \text { (4 sta.) }
\end{aligned}
$$

Fig. 1.-Location of release points for marked $G$. molesta males, who were color-coded by distance of release from central monitoring trap. Two such plots were used, one with a 10 $\mu \mathrm{g}$ - and the other with a $100 \mu \mathrm{g}$-baited monitoring trap. generated for 15 seconds, whereupon five $10 \mu \mathrm{g}$ septa arrayed on $1 / 4$ " mesh screen in a "+ " formation $(5 \mathrm{~cm}$ between the center and 4 outer septa) were introduced $10 \mathrm{~cm}$ upwind of the males to insure their exposure to pheromone. The number of males walking, wing fanning while walking, and flying were recorded. To measure wind velocities the anemometer was held at the cone's open end with the septum-holding device in position upwind. Males were used once and discarded.

To record temperature effects, the same three behav. iors were observed at $14.5^{\circ}, 16^{\circ}$, and $18^{\circ} \mathrm{C}$. A single 10 $\mu \mathrm{g}$ septum was placed $1.5 \mathrm{~m}$ upwind of the cone containing 3 males with the tunnel's fan generating wind at $0.36 \mathrm{~m} / \mathrm{sec}$. Again, males were used only once.

\section{Results}

\section{Mean Maximum Distances of Response Initiation}

The distance from the pheromone source at which previously sitting males first exhibited walking, fanning while walking, or upwind flight varied directly with the source dosage. These mean maximum active distances (Fig. 2) averaged over the entire experiment, showed a consistent pattern: higher dosages evoked responses at significantly greater distances than lower dosages. In still air, the emission rates of Z8-12:Ac loaded at 10, 100 , and $1000 \mu \mathrm{g}$ on septa were $1.2,12$, and $219 \mathrm{ng} /$ $\mathrm{h}(1 \mu \mathrm{g}$ is not known) (Baker et al., 1980) and so ca. a 10 -fold increase in emission rate resulted in slightly greater than a 2 -fold increase in mean maximum active distance for any of the 3 behaviors monitored. R. T. Cardé (1979), using Bossert and Wilson's (1963) equa-

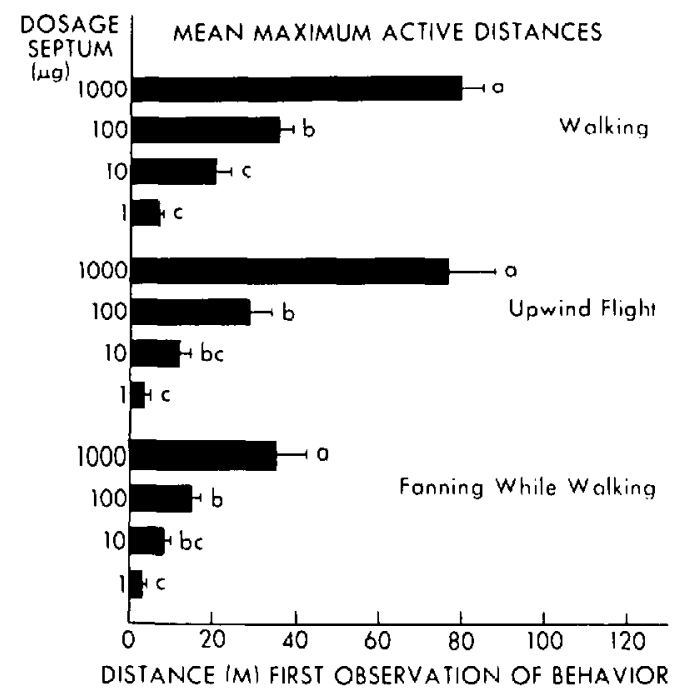

FIG. 2.-Mean maximum active distances of walking, upwind flight, and fanning while walking to four pheromone dosages. For same behavior, means having no letters in common are significantly different according to an analysis of variance with Waller and Duncan's BSD test $(P<0.05)$. Brackets on the means indicate standard error. For $1000,100,10$, and 1 $\mu \mathrm{g}$, respectively, for walking $\mathrm{N}=32,30,30$, and 25 replicates, upwind flight $\mathrm{N}=20,20,22$, and 16 , and for fanning while walking $\mathbf{N}=18,23,30$, and 22 . When a particular behavior did not occur, no value was entered. 
tion, calculated that a 10 -fold increase in pheronone emission rate should elevate the mean maximum active distance 3.7-fold.

Although considerable daily variation occurred, the active distance rankings always followed those of dosage (Fig. 3). These large daily variations appeared to be due to a large extent on temperature effects upon males' response thresholds. Many reports have estimated a $16^{\circ}$ flight threshold for male G. molesta (Armstrong, 1929; Reichart and Bodor, 1972; Rothschild and Minks, 1974). This estimate is supported by our data. On days when the temperature was below $16^{\circ}$, no males took flight, hence the active distance for flight was effectively zero. Furthermore, in the wind tunnel flight initiation behavior at $14.5^{\circ}$ and $16^{\circ}$ was significantly less frequent than at $18^{\circ}$ (Table 1). Other behaviors such as walking also were temperature-affected.

Similarly, wind velocity affected behavior, especially upwind flight, which was totally suppressed at high velocities (Table 2). No wind suppression bias against upwind flight relative to other behaviors should have occurred in the field since the mean wind velocity concurrent with behavioral responses was $0.51 \mathrm{~m} / \mathrm{sec}$ ( \pm .41 S.D.; range among dosages and behaviors 0.32 $0.73 \mathrm{~m} / \mathrm{sec}$ ). Laboratory data suggest that certain velocity ranges may favor expression of one behavior over another (Table 2). However, walking occurred at as great a distance as upwind flight (Fig. 2) in spite of an apparent bias in favor of flight at the lowest velocities, those predominating in the field. This may be explained by the interaction of wind and velocity effects. The fact that walking and upwind flight active distances were greater than fanning while walking implies that the first two behaviors have lower pheromone thresholds than

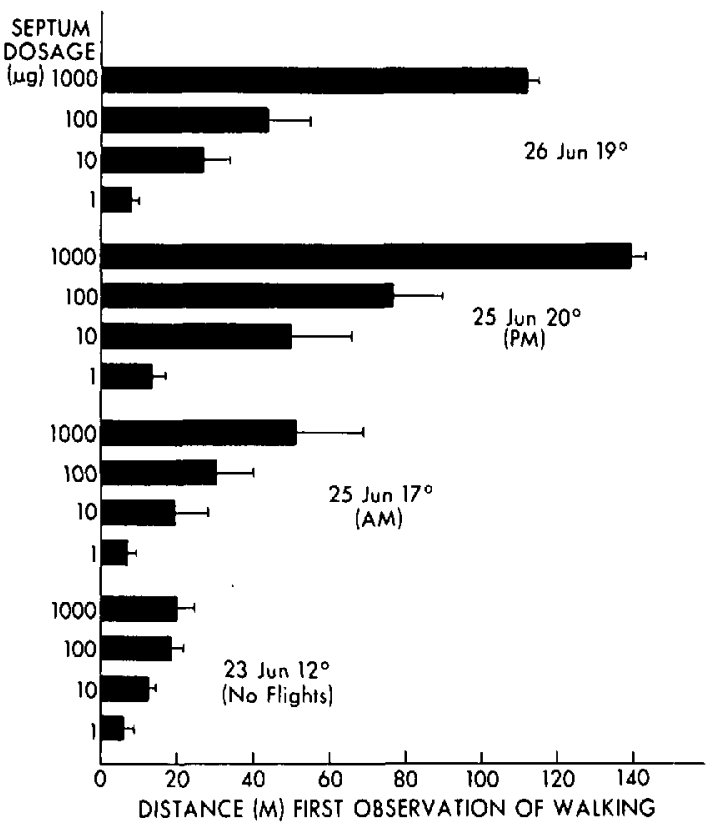

FIG. 3.-Daily variation in maximum active distance for walking apparently influenced by average temperature at the time of the observations. Brackets on means indicate standard error. $\mathrm{N}=3$ for each dosage on each date. Six other observation periods are not shown.
Table 1.-Effect of temperature on the percentage of $G$. molesta males responding to pheromone emitted from a rubber septum impregnated with $10 \mu \mathrm{g}$ of pheromone. Percentages were taken after $30 \mathrm{sec}$ of exposure to pheromone. Percentages in same row having no letters in common are significantly different according to a $\chi^{2} 2 \times 2$ test of independence with Yates' correction $(P<\hat{0.05}) . N=45$ for all treatments.

\begin{tabular}{lccc}
\hline & \multicolumn{3}{c}{ Temperature $\left({ }^{\circ} \mathrm{C}\right)$} \\
\cline { 2 - 4 } & $14.5^{\circ}$ & $16^{\circ}$ & $18^{\circ}$ \\
\hline$\%$ Males flying & $9 \mathrm{c}$ & $42 \mathrm{~b}$ & $100 \mathrm{a}$ \\
$\%$ Males fanning while & & & \\
walking & $7 \mathrm{ab}$ & $20 \mathrm{a}$ & $0 \mathrm{~b}$ \\
$\%$ Males walking & $20 \mathrm{a}$ & $20 \mathrm{a}$ & $0 \mathrm{~b}$ \\
$\%$ Males sitting & $64 \mathrm{a}$ & $18 \mathrm{~b}$ & $0 \mathrm{c}$ \\
\hline
\end{tabular}

the latter under the average wind and temperature conditions of this study.

\section{Average Distance of Upwind Flight Termination}

One interesting result of this study was that although the two higher release rates had longer average maximum active distances than lower rates, the higher rates" active distances did not extend all the way to the source. This was evidenced by a higher percentage of males terminating upwind flight before reaching the source to the 1000 and $100 \mu \mathrm{g}$ septa although just as many males initiated upwind flight as to the $10 \mu \mathrm{g}$ septum (Table 3). R. T. Cardé et al. (1975), using a different blend, observed that fewer males landed near a $1000 \mu \mathrm{g}$ septum compared to $100 \mu \mathrm{g}$ even though equal numbers flew upwind. The average termination distances, 155 and 20 $\mathrm{cm}$ for the 1000 and $100 \mu \mathrm{g}$ septa, respectively (Table 3 ), represent the upper limits of upwind flight active distances as dictated by an apparent upper response threshold in males. This level probably was not reached at lower dosages where premature termination was rare and more likely attributable to visual responses to the septum or too little pheromone. A concentration approaching the lower threshold was occurring $5 \mathrm{~m}$ away from the one $\mu \mathrm{g}$ septum where males were released; only $40 \%$ of the males initiated upwind flight to one $\mu \mathrm{g}$ compared to $83-93 \%$ to the higher dosages.

A composite picture of the data from both experiments illustrates how the average upwind active distances become skewed away from the source as release rate increases (Fig. 4). Applied to trapping strategies, it is clear that increasing the drawing range past a certain limit would have its trade-off in losing "efficiency" at ciose range.

\section{Mark-Release-Recapture}

Recapture frequency by $10 \mu \mathrm{g}$ relative to the $100 \mu \mathrm{g}$ septum was not sharply reduced at greater than $12.2 \mathrm{~m}$, contrary to what we expected from the average drawing ranges measured in the previous experiments (Fig. 5). Instead, the $100 \mu \mathrm{g}$ trap recaptured significantly more of the males released at all distances except at the trap tree. Although dispersal from the release trees could have caused variation in the recapture pattern, the lack of dramatic drop-off in recapture range may be explained by short-term fluctuations in active distance. 
Table 2.-Effect of wind velocity in flight tunnel on the percentage of males responding to 5 septa containing $10 \mu \mathrm{g}$ of pheromone placed $10 \mathrm{~cm}$ upwind of the males. Percentage in same row having no letters in common are significantly different according to a $\chi^{2} 2 \times 2$ test of independence with Yates' correction $(P<0.05)$. N $=21,39,36$, and 33 for the $0.89,1.18,1.73$, and $1.98 \mathrm{~m} / \mathrm{sec}$ treatments, respectively.

\begin{tabular}{llcccc}
\hline & & \multicolumn{5}{c}{ Mean Wind Velocity $(\mathrm{m} / \mathrm{sec})( \pm$ S.D. } \\
\cline { 3 - 6 } & & $0.89( \pm 0.09)$ & $1.18( \pm 0.2 \mathrm{l})$ & $1.73( \pm 0.29)$ & $1.98( \pm 0.31)$ \\
\hline \% Males & $1 \mathrm{sec}$ & $43 \mathrm{a}$ & $13 \mathrm{~b}$ & $6 \mathrm{~b}$ & $0 \mathrm{~b}$ \\
Flying & $5 \mathrm{sec}$ & $78 \mathrm{a}$ & $55 \mathrm{a}$ & $3 \mathrm{~b}$ & $0 \mathrm{~b}$ \\
\% Males & & & & & $3 \mathrm{c}$ \\
Fanning while & $1 \mathrm{sec}$ & $57 \mathrm{a}$ & $71 \mathrm{a}$ & $31 \mathrm{~b}$ & $6 \mathrm{~b}$ \\
walking & $5 \mathrm{sec}$ & $17 \mathrm{ab}$ & $32 \mathrm{a}$ & $14 \mathrm{~b}$ & $64 \mathrm{a}$ \\
\% Males & $1 \mathrm{sec}$ & $0 \mathrm{~b}$ & $8 \mathrm{~b}$ & $53 \mathrm{a}$ & $61 \mathrm{a}$ \\
Walking & $5 \mathrm{sec}$ & $6 \mathrm{~b}$ & $8 \mathrm{~b}$ & $54 \mathrm{a}$ & $33 \mathrm{a}$ \\
\% Males & $1 \mathrm{sec}$ & $0 \mathrm{~b}$ & $8 \mathrm{~b}$ & $0 \mathrm{~b}$ & $33 \mathrm{a}$ \\
Sitting & $5 \mathrm{sec}$ & $0 \mathrm{~b}$ & $5 \mathrm{~b}$ & $29 \mathrm{a}$ & \\
\hline
\end{tabular}

Table 3.-Effect of pheromone dosage on upwind flight approaches to pheromone source by G. molesta males released individually from $5 \mathrm{~m}$ downwind. Thirty males were released to each dosage. Those males reaching the source were scored as approaching to $0 \mathrm{~cm}$.

\begin{tabular}{ccccc}
\hline $\begin{array}{c}\text { Septum } \\
\text { dosage }\end{array}$ & $\begin{array}{c}\overline{\mathrm{X}} \text { Closest approach } \\
\text { to pheromone source }\end{array}$ & $\%$ Upwind flight ${ }^{2}$ & ${\text { Before reaching } 1 \mathrm{~m} \text { away }{ }^{2}}_{\begin{array}{c}\text { Before reaching source } \\
( \pm S . D .)\end{array}}$ \\
\hline $1 \mu \mathrm{g}$ & $8.3 \pm 28.9 \mathrm{~cm} \mathrm{bc}$ & $40 \%(12 / 30) \mathrm{b}$ & $0 \%(0 / 12) \mathrm{b}$ & $8 \%(1 / 12) \mathrm{b}$ \\
$10 \mu \mathrm{g}$ & $1.9 \pm 6.3 \mathrm{~cm} \mathrm{c}$ & $87 \%(26 / 30) \mathrm{a}$ & $0 \%(0 / 26) \mathrm{b}$ & $12 \%(3 / 26) \mathrm{b}$ \\
$100 \mu \mathrm{g}$ & $20.0 \pm 24.15 \mathrm{~cm} \mathrm{~b}$ & $93 \%(28 / 30) \mathrm{a}$ & $4 \%(1 / 28) \mathrm{b}$ & $88 \%(23 / 28) \mathrm{a}$ \\
$1000 \mu \mathrm{g}$ & $154.8 \pm 96.0 \mathrm{~cm} \mathrm{a}$ & $83 \%(25 / 30) \mathrm{a}$ & $56 \%(14 / 25) \mathrm{a}$ & $100 \%(25 / 25) \mathrm{a}$ \\
\hline
\end{tabular}

' Means in same column having no letters in common are significantly different according to the $t$-test $(P<0.05)$.

2 Percentages in same column having no letters in common are significanlly different according to a $\chi^{2} 2 \times 2$ test of independence with Yates' correction $(P<0.05)$.

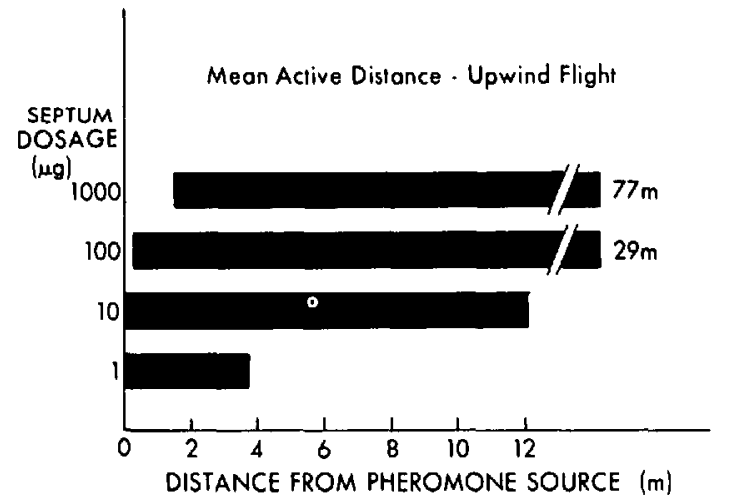

FiG. 4.-A depiction of the mean active distances for upwind flight for the four different septum dosages using a composite of the data from Fig. 2 and Table 3.

Although a time-averaged drawing range can be calculated (Fig. 2), the real-time drawing range may fluctuate daily, hourly, or by the minute as a result of wind and temperature effects on male response threshold. A gust of wind suppressing male flight may send the upwind flight active distance from $100 \mathrm{~m}$ to nearly 0 and back to 100 in a few seconds as it passes. Thus, because the 10 and $100 \mu \mathrm{g}$ active distances should be similarly affected by such meteorlogical fluctuations, the $100 \mu \mathrm{g}$ trap's range should always exceed that of $10 \mu \mathrm{g}$ (Fig. $3)$.

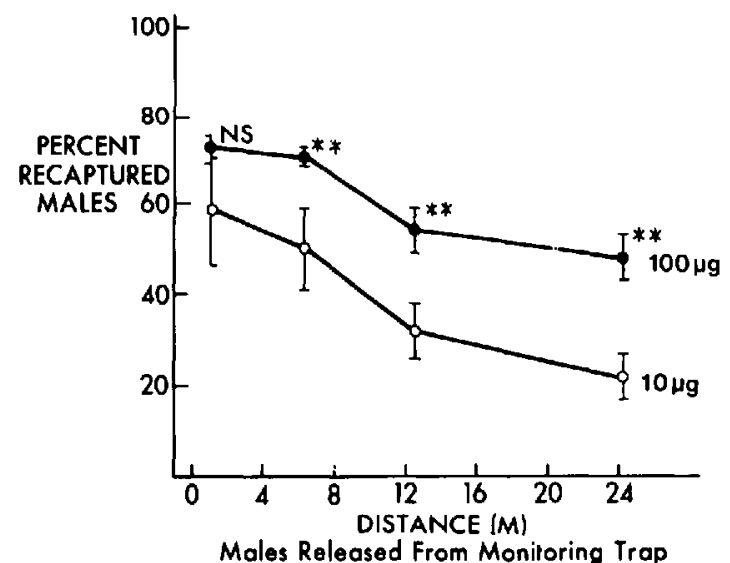

Fig. 5.-Percent recapture of males released at various distances away from a centrally-located monitoring trap containing either a 10 or $100 \mu \mathrm{g}$-baited septum. $\mathrm{N}=85,200,320$, and 320 for the $0,6.1,12.2$, and $24.4 \mathrm{~m}$ release points, respectively.

\section{Discussion}

Sex pheromone lures are usually formulated so that they capture a maximum number of males. These maximal captures result from a trade-off between drawing range and efficiency (males captured divided by number of approaches) that was evident from our data for $G$. molesta. The maximum upwind flight active distance 
(drawing range), increased to greater distances from the source with increased pheromone dosage, but so did termination of upwind flight. Thus, the boundaries of the active distance (Fig. 4) apparently are determined by lower and upper thresholds of male response, as hypothesized from trap catch data by Roelofs (1978) for other species. These thresholds explain why, despite a greater drawing range, traps containing $1000 \mu \mathrm{g}$ capture fewer males than those with $200 \mu \mathrm{g}$ (Roelofs and Cardé, 1974) or $100 \mu \mathrm{g}$ (Baker and Roelofs, unpublished data). Compared to $1000 \mu \mathrm{g}$, traps containing $100 \mu \mathrm{g}$ will have a shorter drawing range, but more males will approach close enough to land and be captured (Fig. 4).

Knowledge of differences in drawing ranges between dosages can be utilized to obtain more accurate withinorchard population estimates by placing monitoring traps far enough from edges so that males are not likely to be attracted from surrounding woods and fields. $G$. molesta is found generally only within orchards, so these considerations are probably not too important for this species, but they may be for more highly polyphagous species. However, for $G$. molesta, the upwind flight active distances indicated that the $10 \mu \mathrm{g}$ septum is ideally suited to monitor smaller areas near edges, corners or in small orchard blocks (Fig. 6). The $20 \mathrm{~m}$ maximum recorded upwind flight active distance (dashed line) is the closest to the edge that $10 \mu \mathrm{g}$-containing traps should be placed although the average active distance is $12 \mathrm{~m}$ (solid line). Conversely, the $100 \mu \mathrm{g}$ dosage may be used in traps placed in the center of larger blocks (Fig. 6) to detect the presence of males over a wider area determined by the $29 \mathrm{~m}$ average active distance. Placement of the trap at least $80 \mathrm{~m}$ from any edge would preclude attracting males from beyond the orchard. Finally, if fine-grained sampling were needed to locate localized high-density populations, a dense grid of small active distance traps such as 1 or $10 \mu \mathrm{g}$ could be deployed.

\section{Factors Affecting the Measurements}

All measurements were made in an open field so that we could measure maximum possible active distances and the measurements from this simplified environment may not be perfectly applicable to an orchard. If they differ though, the orchard distances should be shoiter due to reasons discussed earlier.

Another factor possibly influencing the measurements was subthreshold pre-exposure to pheromone during the observer's walk upwind. Such low-grade exposure also likely occurs under orchard conditions to both trap- and female-emitted pheromone and thus our data may actually be more representative of real monitoring conditions than measurements eliminating such exposure. Our objective was not to describe molecular concentration patterns, a difficult task because male threshold changes must be factored out. Rather, our goal merely was to measure the average maximum active distances which vary with both concertrations and threshold. It appeared that for $G$. molesta wind and temperature-induced threshold variation may have a great influence upon active distance.

\section{Active Space Models}

Nakamura (1976a) attempted to measure the active space of Spodoptera litura (F.) sex pheromone at one

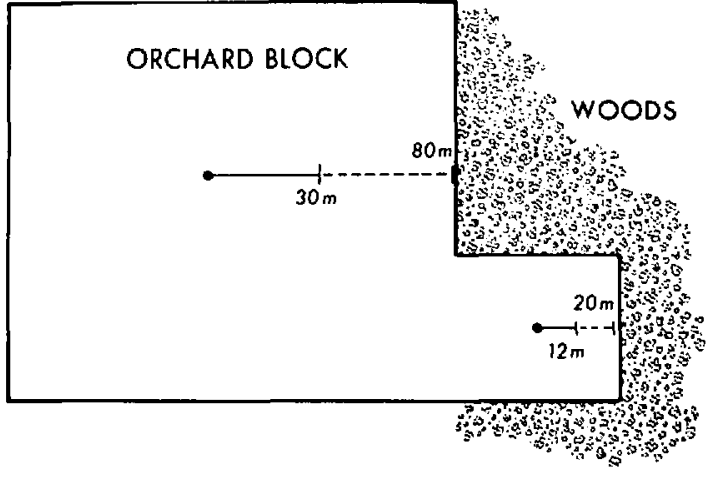

Fic. 6.-A depiction of the possible optimal placement of monitoring traps for $G$. molesta containing the $10 \mu \mathrm{g}$ septum (lower dot) and $100 \mu \mathrm{g}$ septum (upper dot). For both traps the solid line represents the average maximsm drawing range, and the dashed line represents the maximum observed drawing range.

dosage and compared it to the active space generated by calling females. His objectives differed from ours, and included trying to infer molecular concentration changes with wind velocity. Using males in completely enclosed cages, he found that for $S$. litura the average active distance for flight (upwind flight could not be measured within the cages) was ca. $35 \mathrm{~m}$. In contrast to our findings with $G$. molesta (Fig. 2), walking appeared to have the highest threshold, occurring only near the source, whereas wing fanning occurred farther away. Nakamura (1976b, 1979) concluded that a double active space, one long and the other short, corresponding to the two different $S$. litura pheromone components, was the most effective model for explaining male attraction. For $G$. molesta the three components used in this study act as a unit in influencing all stages of behavior (Baker and Cardé, 1979a). Hence, only one active space need be considered, that produced by the entire blend and its corresponding thresholds of initiation and termination of upwind flight.

The equations of Sutton (1953) for molecular diffusion in wind, and Bossert and Wilson (1963) for the corresponding above-threshold molecular concentration, or "active space", have been the most widely used for describing pheromone concentration effects under varying wind conditions. Bossert and Wilson's equation for maximum active distance, $X_{\text {max. }}$, of a continually-emitting pheromone source in moderate wind is:

$$
X_{\text {max }}=\left(\frac{2 \mathrm{Q}}{\mathrm{K} \pi \mathrm{C}_{y} \mathrm{C}_{\mathrm{z}} \mathrm{U}}\right)^{1 / 2-\mathrm{n}}
$$

Where $Q$ is the emission rate, $K$ is the male response threshold, $U$ is the average wind velocity, $C y$ and $C z$ are diffusion constants determined by wind profile and surface roughness, and $n$ is an undetermined constant. Since emission rates, $Q$, for 10,100 , and $1000 \mu \mathrm{g}$ septa of Z8-12:Ac in still air at $23^{\circ} \mathrm{C}$ are $1.2,12$, and $219 \mathrm{ng}$ / h (Baker et al., 1980), these values may be substituted into the above equation for $Q$. Then, solving for $K$ and using the suggested values (Sutton, 1953) of $0.4 \mathrm{~cm}^{1 / 8}$, $0.2 \mathrm{~cm}^{1 / 8}$, and $1 / 4$ for $C y, C z$, and $n$, respectively, the 
three threshold estimates starting with the lowest of the three emission rates are $2.13 \times 10^{-17}, 4.50 \times 10^{-17}$, and $1.50 \times 10^{-16} \mathrm{~g} / \mathrm{cm}^{3}$. A verage wind speed $U$, was $0.51 \mathrm{~m} / \mathrm{sec}$. These values of $K$, within an order of magnitude of each other, indicate that our maximum active distance measurements conform closely to those predicted by the Bossert and Wilson equations. Some possible reasons for the observed variations are: the values substituted for the constants $C y, C z$, and $n$ may not be correct for the average wind speed and surface roughness in our experiments; the emission rate values calculated in still air may not vary linearly with wind velocity; and the initiation of upwind flight in males may have been due to instantaneous peak concentrations rather than the time-averaged concentration required by Sutton's and therefore, Bossert and Wilson's equation.

Using the same formula, we calculated the upper thresholds for upwind flight dictated by the average distance where upwind flight terminated (Table 3). These $X_{m i, r}$ values of 0.20 and $1.55 \mathrm{~m}$ for the 100 and 1000 $\mu \mathrm{g}$ septa ( $Q$ for each as before) result in upper thresholds of $2.7 \times 10^{-13}$ and $1.4 \times 10^{-13} \mathrm{~g} / \mathrm{cm}^{3}$, respectively. Interestingly, the average upper threshold of $2.1 \times 10^{-13}$ $\mathrm{g} / \mathrm{cm}^{3}$ is about 3,000 times higher than the average lower threshold, $7.2 \times 10^{-17} \mathrm{~g} / \mathrm{cm}^{3}$. Thus, for this blend, the active distance boundaries for upwind flight are dictated by threshold limits differing by only a little more than 3 orders of magnitude, seemingly a narrow concentration range. The data for termination of upwind flight give an idea of the steepness of the time-averaged concentration gradient near the source (Table 3 ). Assuming a constant threshold, an 18-fold increase in effective concentration (12 ng/hr to $219 \mathrm{ng} / \mathrm{hr}$ ) must have occurred in the 135 $\mathrm{cm}$ from $20 \mathrm{~cm}$ to $155 \mathrm{~cm}$ from the source where upwind flight stopped. Clearly, Bossert and Wilson's model must be altered so that active space is defined as the space where pheromone concentration is within both lower and upper thresholds for a particular behavior.

We do not know whether other blends have more restricted threshold ranges and correspondingly narrower active distance boundaries, but field observations of males flying upwind to a range of $(E)-(Z)$ ratios indicate that the upper threshold is probably lower to treatments with increasing $(E)$ (Baker and Cardé, 1979a). Males did not approach as closely to the dispenser, exhibiting reduced tolerance to too much $(E)$. This should create a more restricted active distance, provided the lower threshold did not also become lower, and would explain reduced male captures to those blends (Baker and Cardé, 1979a). On the other hand, trap catch data from a variety of species implies that non-optimal blends can duplicate the threshold span of the optimal blend, but behavioral observations are needed to test this hypothesis (Roelofs 1978).

It is clear that for a particular blend in pheromone trapping, exploiting the full range of emitted concentrations between the lower and upper thresholds would be desirable for trapping over the widest possible area, whereas an emission concentration slightly above the lower threshold would be best when a smaller drawing range is needed. Further work should provide insight as to how changes in blend quality alter the range of be- haviorally "active" concentrations delimiting an active space.

\section{Acknowledgment}

We thank W. Meyer for excellent technical assistance in the field and laboratory, and F. Wadhams, B. Carney, and $\mathrm{K}$. Poole for rearing $G$. molesta adults.

\section{REFERENCES CITED}

Armstrong, T. 1929. Notes on the life history of the Oriental peach moth at Vineland Station. Rep. Entomol. Soc. Ont. 59: $65-72$.

Baker, T. C., and R. T. Cardé. 1979a. Analysis of pheromone-mediated behavior in male Grapholitha molesta, the Oriental fruit moth, (Lepidoptera: Tortricidac). Environ. Entomol. 8: 956-68.

Baker, T. C., and R. T. Cardé, 1979b. Endogenous and exogenous factors affecting female calling and male sex pheromone response in Grapholitha molesta (Busck). J. Insect Physiol. 25: 943-50.

Baker, T. C., R. T. Cardé, and J. R. Miller. 1980. Oriental fruit moth pheromone component release rates measured after collection by glass surface absorption. J. Chem. Ecol. 6: 749-58.

Biwer, G., C. Descoins, and M. Gallois. 1979. Etude des constituants volatils presents dans la glande productrice de pheromone de la femelle vierge de Grapholitha molesta Busck, Lepidoptere tortricidae (Olethreutinae) C. R. Acad. Sc. Paris, t. 288: 413-6.

Bossert, W. H., and E. O. Wilson. 1963. The analysis of olfactory communication among animals. J. Theoret. Biol. 5: 443-69.

Cardé, A. M., T. C. Baker, and R. T. Cardé. 1979. Identification of a four-component sex pheromone of the female Oriental fruit moth, Grapholitha molesta (Lepidoptera: Tortricidae). J. Chem. Ecol. 5: 423-7.

Cardé, R. T. 1979. Behavioral responses of moths to femaleproduced pheromones and the utilization of attractantbaited traps for population monitoring. In R. L. Rabb and G. G. Kennedy (eds.). Movement of highly mobile insects: concepts and methodology in research. North Carolina St. Univ., pp. 286-301.

Cardé, R. T., T. C. Baker, and W. L. Roelofs. 1975. Ethological function of components of a se - attractant system for Oriental fruit moth males, Grapholitha molesta (Lepidoptera: Tortricidae). J. Chem. Ecol. 1: 475-91.

Miller, J. R., and W. L. Roelofs. 1978. Sustained-flight tunnel for measuring insect responses to wind-bome sex pheromone. J. Chem. Ecol. 4: 187-98.

Nakamura, K. 1976a. The effect of wind velocity on the diffusion of Spodoptera litura (F.) sex pheromone. Appl. ent. Zool. 4: 312-9.

Nakamura, K. 1976b. The active space of the pheromone of Spodoptera litura and the attraction of adult males to the pheromone source, pp. 145-55. "Insect Pheromones and Their Applications." Proceedings of a symposium on insect pheromones and their applications. Nagaoka and Tokyo. December 8-11, 1976.

Nakamura, K. 1979. Effect of the minor component of the sex pheromone on the male orientation to pheromone source in Spodoptera litura (F.), Xemop. Hac. 4: 153-6.

Reichart, G., and J. Bodor. 1972. Biology of the Oriental fruit moth (Grapholitha molesta Busck) in Hungary. Acta Phytopathol. Acad. Sci. Hung. 7: 279-95.

Reidl, H., B. A. Croft, and A. J. Howitt. 1976. Forecasting codling moth phenology based on pheromone trap catches and physiological-time models. Can. Entomol. 108: 44960. 
Roelofs, W. L. 1978. Threshold hypothesis for pheromone perception. J. Chem. Ecol. 4: 685-99.

Roelofs, W. L., and R. T. Cardé. 1974. Oriental fruit moth and lesser appleworm attractant mixtures refined. Environ. Entomol. 3: 586-8.

Roelofs, W. L., A. Comeau, and R. Selle. 1969. Sex pheromone of the Oriental fruit moth. Nature 244: 723.

Rothschild, G. H. L., and A. K. Minks. 1974. Time of activity of male Oriental fruit moths at pheromone sources in the field. Environ. Entomol. 3: 1003-7.

Sutton, O. G. 1953. "Micrometeorology." McGraw-Hill, New York. 333 pp.

Welch, S. M., B. A. Croft, J. F. Brunner, and M. F. Michels. 1978. PETE: an extension phenology modeling system for management of multi-species pest complex. Environ. Entomol. 7: 487-94. 